\title{
Extramedullary Spinal Neurosarcoidosis: Report of Two Cases
}

\author{
Raffaele Nardone ${ }^{a}$ Alessandro Venturi ${ }^{\mathrm{b}}$ Ebba Buffone ${ }^{\mathrm{a}}$ Piergiorgio Lochner $^{\mathrm{a}}$ Roland Marth ${ }^{\mathrm{a}}$ \\ Igor Florio ${ }^{a}$ Konrad Psenner ${ }^{b}$ Frediano Tezzon $^{a}$ \\ Departments of a Neurology and ${ }^{\mathrm{b}}$ Radiology, F. Tappeiner Hospital, Merano, Italy
}

Dear Sir,

Sarcoidosis is a chronic systemic disorder of unknown etiology characterized in affected organs by an accumulation of epithelioid granulomas without caseation or staining for infectious agents and derangement of the normal tissue architecture [1]. These granulomas often incorporate multinucleated giant cells and lymphocytes. In the past decade, there has been significant progress in our understanding of the immunopathogenesis of the disease, but the etiology of this enigmatic condition still eludes us.

Clinical neurological involvement occurs in approximately $5 \%$ of patients. However, autopsy results suggest that subclinical involvement may be present in up to $25 \%$ of patients. Neurosarcoidosis is a great mimicker and an uncommon presentation of sarcoidosis; it is therefore a diagnostic challenge, especially when there is no prior history of systemic sarcoidosis [2-8].

A typical imaging feature is thickening and enhancement of the basilar leptomeninges of the brain. Other imaging findings, such as enhancing or nonenhancing parenchymal lesions, dural and bone lesions may occur in the head and spine.

Spinal sarcoidosis is a rare condition, whose natural history and therapeutic outcome are still not fully known, and extramedullary extradural mass formation is even rarer. We describe 2 additional cases of spinal extramedullary sarcoid lesions and discuss the diagnostic approach and therapeutic management of this condition.

\section{Case Reports}

Patient 1. An 80 year-old woman was admitted to our department for a sudden onset of a sensorimotor deficit in her right upper and lower limbs; she also complained of neck pain radiating into her right shoulder. The patient presented a sarcoidosis of the lung with hylar and mediastinal lymphadenopathy, and anterior uveitis, diagnosed in 1994. Sarcoid pathology of noncaseating granuloma with giant cells was detected in the lung biopsy specimen. She was treated with oral steroids for 1 year; for the last 10 years there had been no signs of disease.

Neurological examination revealed right-sided hemiplegia and severe hypesthesia over the left side. The plantar response was extensor on the right side. Computed tomography of the brain and cervical spine was normal; magnetic resonance imaging (MRI) of the cervical spinal cord revealed a mass that was extramedullary in the right lateral aspect of the spinal canal at the level $\mathrm{C}_{2}-\mathrm{C}_{3}$ and compressing the spinal cord (fig. 1a-c). Surprisingly the plasma level of angiotensin-converting enzyme (ACE) was low (3 IU/1). An intravenous corticosteroid therapy $(250 \mathrm{mg} /$ day methylprednisolone for 5 days) was started, followed by a 40-mg daily dose of oral prednisone (approx. $1 \mathrm{mg} / \mathrm{kg}$ per day), then gradually tapered to $5 \mathrm{mg}$ /day over 2 months. A dramatic improvement was seen on follow-up MRI (fig. 2a, b); neuroradiological findings corresponded to this clinical improvement.

Patient 2. A 52-year-old woman presented with a 2-month history of progressive back pain, numbness and weakness in her lower extremities. Difficulty in micturition was noted. Neurological examination revealed right-side dominant spastic paraparesis and a left-side dominant decrease in sensation to pain and touch below the level of $\mathrm{T}_{4}$. Vibration and position senses were also disturbed, especially on her right side. Deep tendon reflexes were hyperactive on the lower limbs, especially on the right side. Plantar responses were extensor on both sides.

No evidence of systemic illness was noted concomitant with the patient's onset of neurological symptomatology.

MRI revealed an extramedullary and extradural lesion extending at the level $\mathrm{T}_{2}-$ $\mathrm{T}_{6}$ and encasing the dorsal cord from the anterior, posterior and right lateral aspects, mimicking an en plaque meningio-

\section{KARGER}

Fax +4161306 1234 E-Mail karger@karger.ch www.karger.com
(C) 2005 S. Karger AG, Base 0014-3022/05/0544-0220\$22.00/0

Accessible online at:

www.karger.com/ene
Dr. Raffaele Nardone

Department of Neurology, F. Tappeiner Hospital

Via Rossini, 5

IT-39012 Merano (Italy)

Tel. +39 0473264 616, Fax +39 0473264 449, E-Mail raffaele.nardone@asbmeran-o.it 

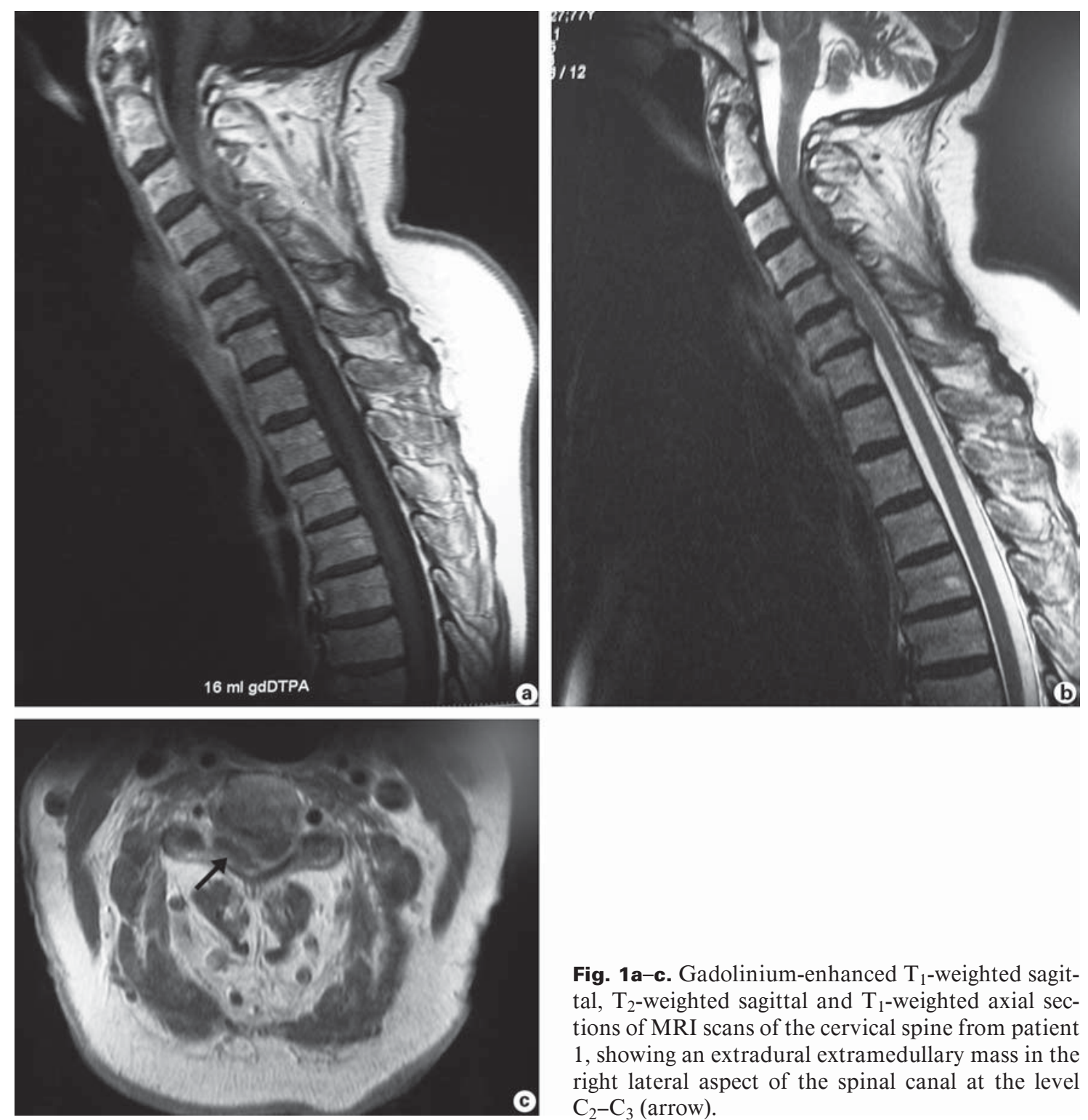

Fig. 1a-c. Gadolinium-enhanced $\mathrm{T}_{1}$-weighted sagittal, $\mathrm{T}_{2}$-weighted sagittal and $\mathrm{T}_{1}$-weighted axial sections of MRI scans of the cervical spine from patient 1 , showing an extradural extramedullary mass in the right lateral aspect of the spinal canal at the level $\mathrm{C}_{2}-\mathrm{C}_{3}$ (arrow).

ma (fig. 3a-d). The thecal sac was narrowed by the extradural mass; the enhancing mass was wrapping around the thecal sac.

Considering the shape of the lesion, a differential diagnosis of granulomatous lesion-like tuberculosis, meningioma, lymphoma as well as epidural metastases was taken into account. There were no associated bony changes as often seen in the case of lymphoma or tuberculosis.

The patient underwent thoracic laminectomy and biopsy of the spinal pathology, which revealed noncaseating granulomas consistent with sarcoidosis. Appro- priate testing did not reveal systemic involvement of sarcoidosis. ACE was 22 IU/1 (normal limit 20 IU/1). The cerebrospinal fluid ACE level was elevated (4.8 $\mu \mathrm{mol} / 1 / \mathrm{min})$.

A high-dose methylprednisolone therapy ( $1 \mathrm{~g} /$ day for 5 days) was given, followed rapidly by almost complete neurological recovery; successively a daily dose of $60 \mathrm{mg}$ prednisone (approx. $1 \mathrm{mg} / \mathrm{kg}$ per day) was orally administered for 7 days, then reduced to $20 \mathrm{mg}$ daily.

The plasma ACE level decreased to a normal level of 11 IU/1. Follow-up MRI ex- amination after 1 year did not show any abnormalities.

\section{Discussion}

The cases that we described are 2 examples of the protean and difficult-to-recognize presentation that neurosarcoidosis may adopt. Neurosarcoidosis has a variable expression, which tends to mimic other neurological diseases. Neurological manifestations occur usually as a part of the spectrum of the systemic disease; the diagnosis is based on the documentation of systemic sarcoidosis in the absence of other neurological diseases. 

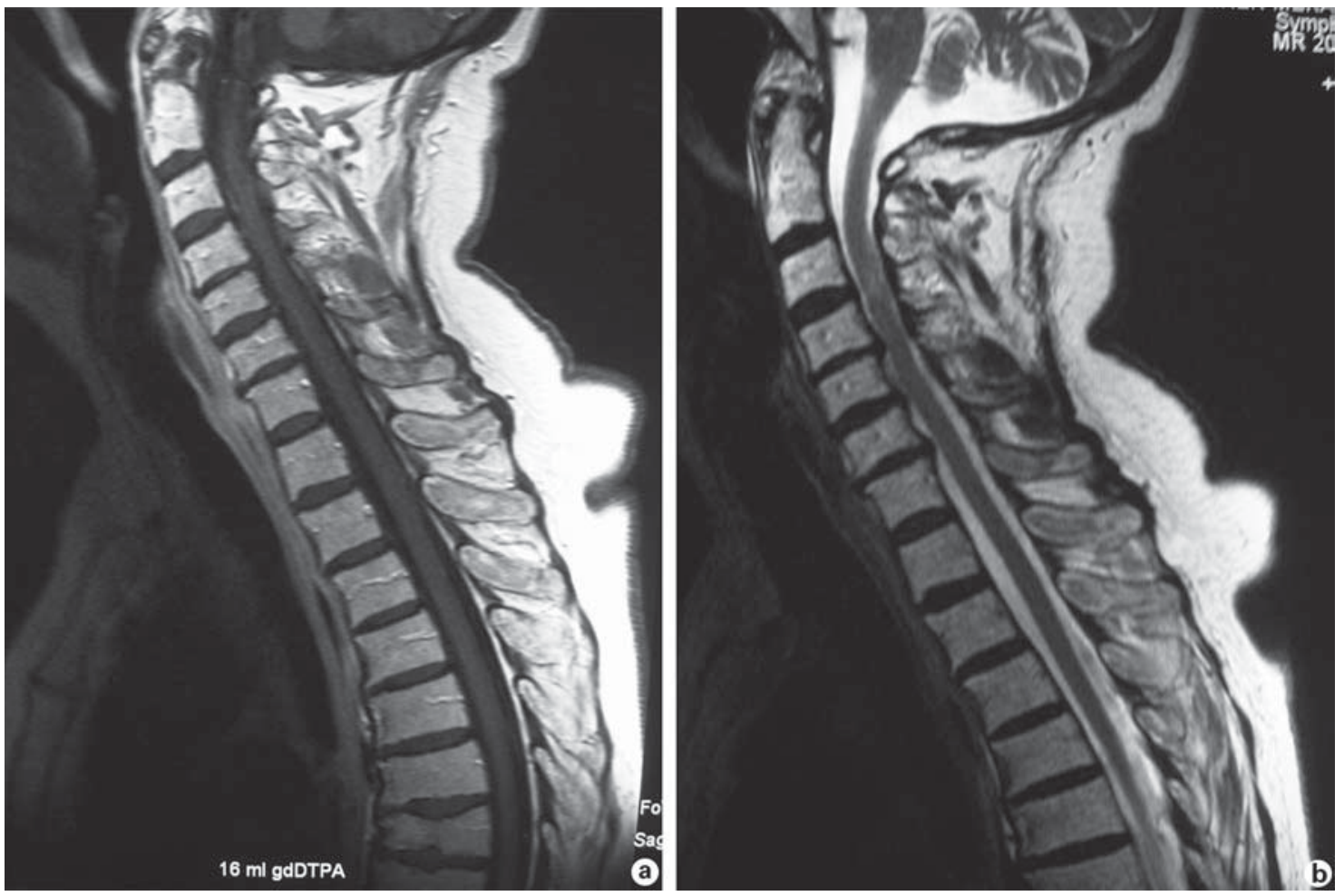

Fig. 2a, b. Gadolinium-enhanced DTPA $T_{1}$-weighted sagittal and $T_{2}$-weighted sagittal sections of MRI scans of the cervical spine from patient 1, 2 months after the initiation of the corticosteroid therapy; the extradural extramedullary mass is not observed.

However, patients with systemic disease may initially present with neurological symptoms, and, rarely, the sarcoidosis may be isolated to the CNS.

Spinal cord involvement is extremely rare, occurring in only $0.3-0.4 \%$ of patients with systemic sarcoidosis [9-11]. Moreover, most spinal sarcoid lesions are intramedullary, only a few cases of extramedullary sarcoid lesions have been reported [1215]. Because of its nonspecific clinical presentation and neuroradiological imaging characteristics, spinal sarcoidosis remains a very difficult diagnosis. However, its occurrence should always be considered and ruled out if systemic sarcoidosis is known. Very rarely sarcoid granulomatosis is strictly confined to the CNS; spinal sarcoidosis may also be the first and only manifestation of the disease and mimic various spinal cord diseases. Therefore, when a mass is present in the spinal canal, it is important to remain open to the possibility of spinal sarcoidosis, even in the absence of systemic signs of disease.
Our report confirmed the role of MRI in diagnosing intraspinal sarcoidosis, but the findings are nonspecific and must be considered with the clinical course of the patient in arriving at the correct diagnosis.

Corticosteroids are commonly used to treat systemic sarcoidosis; however, the effectiveness of corticosteroid therapy for spinal cord sarcoidosis has not yet been established. It has been previously reported that, in patients in whom initial corticosteroid therapy was delayed, MRI findings were dramatically improved after therapy, while the clinical course was not favorable [16, 17]. In agreement with these findings, the use of intravenous cortisone has resulted in an excellent outcome for both patients who started the therapy in the relatively early phase. Additional immunosuppressive drugs were also not necessary.

It can be hypothesized that, after the therapy, inflammation abates and granulomas disappear, but irreversible changes, such as gliofibrosis of the lesion and de- struction of the neural pathways, may lead to prolonged myelopathic symptoms. Therefore, corticosteroid therapy should be initiated as early as possible before the spinal cord parenchymal damage becomes irreversible, to enhance the chance of a complete recovery of the spinal cord.

Unlike intramedullary sarcoid lesions, an extramedullary lesion can be totally removed. However, our report indicates that, in the unusual case of spinal extramedullary sarcoidosis, corticosteroid therapy should be considered as the first therapeutic option and has to be recommended prior to aggressive surgical management involving the removal of the extradural mass. To conclude, it is important to consider and establish the diagnosis of neurosarcoidosis as early as possible, because early recognition of this condition may lead to subsequent immediate and appropriate treatment with steroids.
Nardone/Venturi/Buffone/Lochner/ Marth/Florio/Psenner/Tezzon 

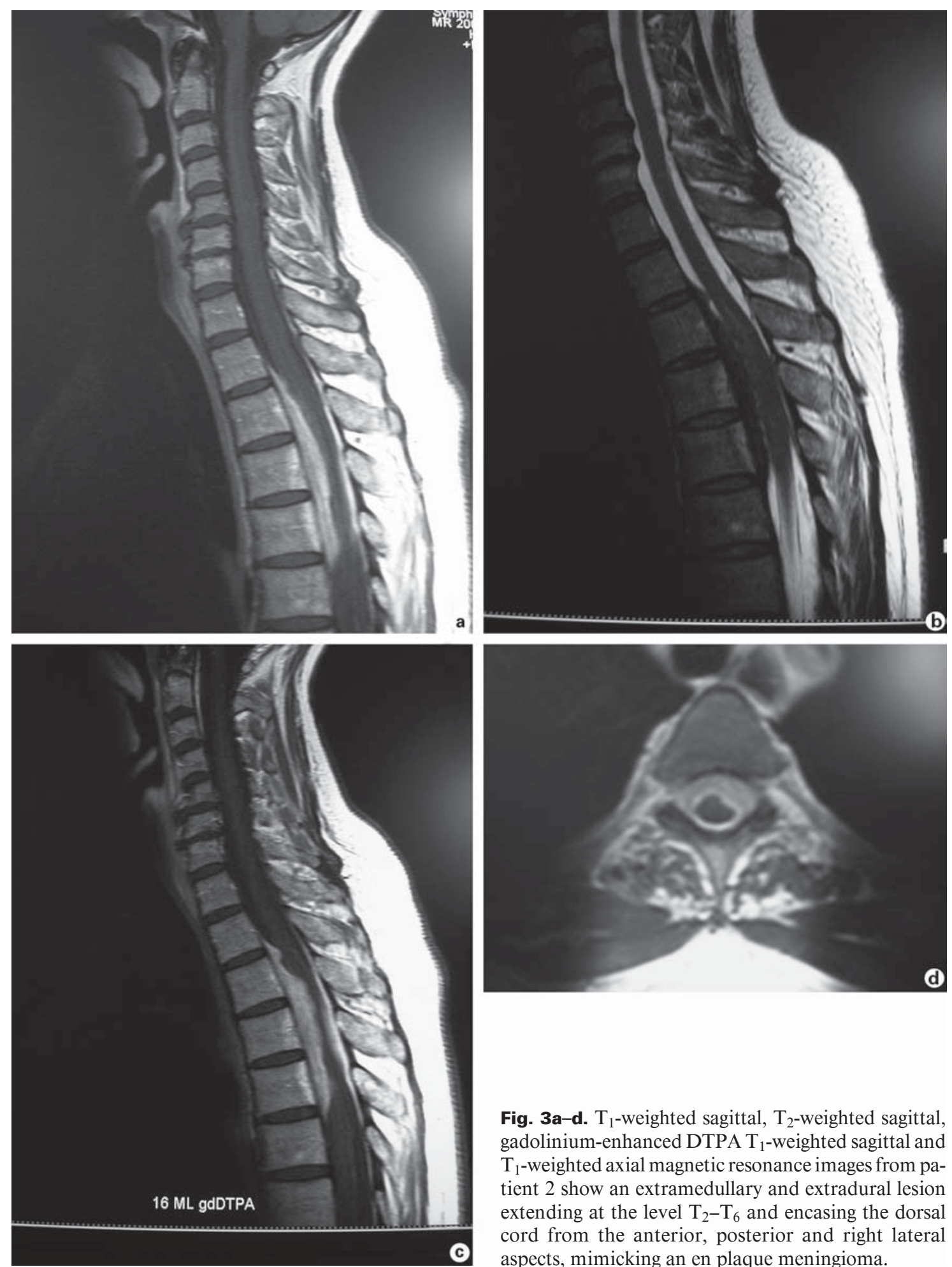

Fig. 3a-d. $\mathrm{T}_{1}$-weighted sagittal, $\mathrm{T}_{2}$-weighted sagittal, gadolinium-enhanced DTPA $\mathrm{T}_{1}$-weighted sagittal and $\mathrm{T}_{1}$-weighted axial magnetic resonance images from patient 2 show an extramedullary and extradural lesion extending at the level $\mathrm{T}_{2}-\mathrm{T}_{6}$ and encasing the dorsal cord from the anterior, posterior and right lateral aspects, mimicking an en plaque meningioma. 


\section{References}

1 Dantzker DR, Tobin MJ, Whatley RE: Respiratory diseases; in Andreoli TE, Carpenter CCJ, Plum F, Smith LH (eds): Cecil Essentials of Medicine. Philadelphia, Saunders, 1986, p 149.

2 Siltzbach LE, James DG, Neville E, Turiaf J, Battesti JP, Sharma OP, Hosoda Y, Mikami R, Okoda M: Course and prognosis of sarcoidosis around the world. Am J Med 1974;57:847852

3 Delaney P: Neurological manifestations in sarcoidosis: a review of the literature, with report of 23 cases. Ann Intern Med 1977;87:336345 .

4 Cahill DW, Salcman M: Sarcoidosis: a review of the rarer manifestations. Surg Neurol 1981; 15:204-211.

5 Stern BJ, Krumholz A, Johns C, Scott P, Nissan J: Sarcoidosis and its neurologic manifestations. Arch Neurol 1985;42:909-917.
6 Sharma OP, Sharma AM: Sarcoidosis of the nervous system: a clinical approach. Arch Intern Med 1991;151:1317-1321.

7 Oksanen VE: Neurosarcoidosis; in James DG (ed): Sarcoidosis and Other Granulomatous Disorders. New York, Dekker, 1994, pp 285309.

8 Newman LS, Rose CS, Meier LA: Review article: sarcoidosis. N Engl J Med 1997;336: 1224-1234.

9 Silverstein A, Feuer MM, Silzbach LE: Neurologic sarcoidosis: study of 18 cases. Arch Neurol 1965;12:1-11.

10 Slade WR: Sarcoid of the nervous system. J Natl Med Assoc 1979;71:1205-1208.

11 Bogousslavsky J, Hungerbuehler JP, Regli F, Graf HJ: Subacute myelopathy as the presenting manifestation of sarcoidosis. Acta Neurochir (Wien) 1982;65:193-197.

12 Weissman MN, Lange R, Kelley C, Belgea K, Abel L: Infraspinal epidural sarcoidosis: case report. Neurosurgery 1996;39:179-181.
13 Connor SE, Marshman L, Al-Sarraj S, Ng V: MRI of a spinal intradural extramedullary sarcoid mass. Neuroradiology 2001;43:10791083.

14 Bose B: Extramedullary sarcoid lesion mimicking intraspinal tumor. Spine J 2002;2:381385.

15 Hamasaki T, Noda M, Kamei N, Yamamoto S, Ochi M, Yasunaga Y: Intradural extramedullary mass formation in spinal cord sarcoidosis: case report and literature review. Spine 2003;28:E420-E423.

16 Stern BJ, Krumholz A, Johns C, Scott P, Nissim J: Sarcoidosis and its neurological manifestations. Arch Neurol 1985;42:909-915.

17 Koike H, Misu K, Yasui K, Kaneyama T, Ando T, Yanagi T, Sobue G: Differential response to corticosteroid therapy on MRI findings and clinical manifestations in spinal cord sarcoidosis. J Neurol 2000;247:544-549. 